Article

\title{
Status of Gastric Mucosa and Liver in Mice upon Treatment with Diclofenac Sodium
}

\author{
Md. Nazmul Hoque ${ }^{1}$, Md. Kamrul Islam², Md. Monirul Islam ${ }^{3}$, Md. Mustafizur Rahman \\ Chowdhury ${ }^{4}$,Md.Mizanur Rahman ${ }^{5}$
}

\begin{abstract}
Background: Diclofenac sodium is a non-steroidal anti-inflammatory drug with reportedly undesirable harmful side effects including blood disorders, abdominal pain, ulceration and bleeding of the stomach or intestine. Objective:The present study was conducted to investigate the effect of diclofenac sodium on erythropoiesis, on stomach and liver under different conditions. Method: This experimental study on animal model was conducted in the Department of Physiology, Bangladesh Agricultural University, Mymensingh, between July and August 2007. A total of 45 Swiss Albino mice were randomly assigned into five equal groups $(\mathrm{n}=9)$ and they all were fed with standard broiler pellet (25 $\mathrm{gm} /$ mice/day) throughout the experimental period of 40 days. Keeping 1 group as control(groupA), 4 groups were treated with diclofenac sodium @ $3 \mathrm{mg} / \mathrm{kg}$ body weight (bwt) orally in empty (group B)or full stomach with (group c) or without vitamin B12(group D) @ $10 \mu \mathrm{g} / \mathrm{Kg}$ body weight through intramuscular route. Total erythrocyte count (TEC) and $\mathrm{Hb} \%$ was determined to assess erythropoiesis. Macroscopic and microscopic changes of liver and stomach were studied by standard laboratory method. Data were analyzed statistically by ANOVA and un paired $t$ test. Result: Oral administration of this drug significantly $(p<0.01)$ decreased Total Erythrocyte Count(TEC) and Hb in the animals treated with diclofenac sodium in empty stomach and in the animals treated with diclofenac sodium plus vitamin B12 in empty stomach. All the treated mice showed slight to moderate congestion of the gastric mucosa and liver. Conclusion: Intake of diclofenac sodium in empty stomach may produce harmful side effect on stomach and liver.
\end{abstract}

Key words: Stomach, Mice, Diclofenac sodium.

J Bangladesh Soc Physiol. 2010 December; 5(2): 89-93 For author affiliations, see end of text.

http://www.banglajol.info/index.php/JBSP

\section{Introduction}

D iclofenac sodium is a non-steroidal anti-inflammatory drug designed by selection of appropriate physicochemical and steric properties. Its pharmacologic activity, specifically its effects in acute and sub-chronic inflammation and its analgesic activity have been assessed in animal models. The tolerability of the compound as judged by several parameters (i.e., ratio between the acute lethal dose or the dose inducing gastrointestinal blood loss and the desired pharmacologic activity) is favorable in comparison with other non-steroidal antiinflammatory drugs. Diclofenac is used to relieve pain and inflammation in a wide range of conditions, including arthritis, gout, sprains, fractures, back pain and following minor surgery.

All the medicines in the NSAIDs group reduce inflammation caused by the body's own immune system and are effective painkillers, but must be taken with or after food to avoid stomach related side effects ${ }^{1-2}$. The pharmacologic effects of this drug include analgesia, antipyresis, and control of inflammation. This drug induce undesirable 
and potentially life-threatening side effects including blood disorders, constipation, nausea, vomiting or abdominal pain, indigestion (dyspepsia), ulceration of the stomach or intestine, inflammation of the liver (hepatitis), loss of appetite, bleeding from the stomach or intestine , decreased kidney function, and alteration in results of liver function tests ${ }^{3-4}$. Severe gastric disorder may result in vitamin $\mathrm{B}_{12}$ deficiency which in turn causes folic acid unavailable to operate several metabolic functions including eryhropoiesis. Finally macrocytic normochromic anemia is developed due to vitamin $B_{12}$ deficiency $^{5}$. The detailed information on the adverse drug reactions of diclofenac sodium is almost lacking in most laboratory animals particularly in mice. And hence the research work was carried out to study the effect of diclofenac sodium on some organs such as stomach and liver.

\section{Methods}

This experimental study was conducted in the Department of Physiology, Bangladesh Agricultural University, Mymensingh between July 2007 and August 2007 for a period of 40 days. For this,a total of 45 healthy Swiss albino mice were randomly divided into 5 equal groups $(n=9)$ and numbered them as group A, B, C, D, E and kept group wise in 5 separate cages. All groups were supplied with standard broiler pellet (25 gm/mice/day) and fresh drinking water (10 $\mathrm{ml} /$ mice/day) throughout the experimental period. Out of five groups, one group of mice (Group A) was kept as control without giving any treatment. The remaining 4 groups were treated with diclofenac sodium @ 3 mg/kg bwt orally. Group $\mathrm{B}$ was treated in empty stomach whereas group $\mathrm{C}$ was treated in full stomach. In group D and E, animals were further treated with vitamin $\mathrm{B}_{12} @$ $10 \mu \mathrm{g} / \mathrm{Kg}$ bwt intramuscularly (i/m) in empty stomach and in full stomach respectively in addition to diclofenac sodium .

For estimation of $\mathrm{Hb}$ and Total Erythrocyte Count (TEC) the $2 \mathbf{~ m l}$ blood was collected from tail on day 1 and day 20. At the end of experimental period (day 40) the mice were kept fasting overnight. A set of sterile test tubes containing anticoagulant (Double oxalate salt) at a ratio of 1:10 were taken. The blood was collected directly from heart at this time. The blood was kept in refrigerator till examination was done. Hematological studies were performed within two hours of blood collection. On this day, the mice of all groups were sacrificed using anaesthetic, diethyl ether overdose and gross pathological and histopathological changes in liver and stomach were studied as per routine method after preserving in 10\% buffered formaline. Data were expressed as mean \pm standard deviation. For statistical analysis one way ANOVA and unpaired t test were employed.

\section{Results}

Total erythrocyte count (TEC) values are presented in Table I. Among these values, the highest mean value was recorded in group $\mathrm{E}$ on the day 40 (7.15 \pm 0.08$)$ and the lowest mean value was recorded in in group $\mathrm{D}$ on the day 40 (5.68 \pm 0.26$)$ and also group $B(5.78 \pm 0.2)$ on the day 40 . The highest and lowest value recorded had a gross fluctuation and they were statistically significant $(\mathrm{P}<0.01)$.

Mean hemoglobin content (gm/dl) is presented in Table II. Among these values, lowest value in group B (8.98 \pm 0.21$)$ and the highest value in group E (13.04 \pm 0.19$)$ was recorded on the day 40.The obtained highest and lowest value showed a gross fluctuation and they were statistically significant $(\mathrm{P}<0.01)$.

In group $\mathbf{B}$ \&D gross examination of empty stomached animal showed that liver became enlarged, pale, friable and congested with hemorrhage and ulceration was found in the gastric mucosa.(Figure 1,2)

In the present study, histopathological examination of liver and stomach samples in all groups were done for the detection of pathological lesion if any. In empty stomached animal(group B,D) the lesion observed in liver section includes central vein congestion, sinusoidal congestion, infiltration of mononuclear cells around central vein, slightly swollen hepatocytes and fatty changes characterized by minute vaculation in liver. (Figure 3,4) 
Table I. Total Erythrocyte Count $\left(\right.$ x $\left.10^{6} / \mathrm{mm}^{3}\right)$ in different groups of mice(total $\left.\mathrm{n}=45\right)$

\begin{tabular}{llccr}
\hline Group & Treatment & \multicolumn{3}{c}{ Days } \\
\cline { 3 - 5 } & & Pre treatment & Post treatment \\
& & Day 1 & Day 20 & Day 40 \\
\hline $\mathrm{A}(\mathrm{n}=5)$ & Control & $6.54^{\mathrm{bcd}} \pm 0.1$ & $6.85^{\mathrm{abc}} \pm 0.2$ & $6.38^{\mathrm{cd}} \pm 0.16$ \\
$\mathrm{~B}(\mathrm{n}=5)$ & Diclofenac Sodium before meal & $6.87^{\mathrm{abc}} \pm 0.2$ & $6.29^{\mathrm{d}} \pm 0.11$ & $5.78^{\mathrm{e}} \pm 0.25^{* *}$ \\
$\mathrm{C}(\mathrm{n}=5)$ & Diclofenac Sodium after meal & $6.84^{\mathrm{abc}} \pm 0.11$ & $6.17^{\mathrm{de}} \pm 0.38$ & $6.17^{\mathrm{de}} \pm 0.38$ \\
$\mathrm{D}(\mathrm{n}=5)$ & Diclofenac Sodium plus Vitamin $\mathrm{B}_{12}$ before meal & $6.35^{\mathrm{cd}} \pm 0.25$ & $5.73^{\mathrm{e}} \pm 0.20^{* *}$ & $5.68^{\mathrm{e}} \pm 0.26^{* *}$ \\
$\mathrm{E}(\mathrm{n}=5)$ & Diclofenac Sodium plus Vitamin $\mathrm{B}_{12}$ after meal & $6.59^{\mathrm{cd}} \pm 0.48 \mathrm{~b}$ & $7.01^{\mathrm{ab}} \pm 0.87$ & $7.15^{\mathrm{a}} \pm 0.08^{* *}$ \\
\hline
\end{tabular}

The values given above represent the mean \pm standard deviation (SD) of 9 mice $(n=9)$

$* *=$ Significant at $\mathrm{p}<0.01 \quad *=$ Significant at $\mathrm{p}<0.05$

abcde -??

Statistical test-??

Table II. Hemoglobin content (gm/dl) of different groups of mice.

\begin{tabular}{llccc}
\hline Group & Treatment & \multicolumn{3}{c}{ Days } \\
& & Pre treatment & Post treatment \\
& & Day 1 & Day 20 & Day 40 \\
\hline A & Control & $12.60^{\mathrm{cd}} \pm 0.32$ & $12.71^{\mathrm{c}} \pm 0.14$ & $12.76^{\mathrm{bc}} \pm 0.06$ \\
B & Diclofenac Sodium before meal & $12.39^{\mathrm{d}} \pm 0.37$ & $10.67^{\mathrm{g}} \pm 0.44$ & $8.98^{\mathrm{h}} \pm 0.21^{* *}$ \\
C & Diclofenac Sodium after meal & $12.96^{\mathrm{ab}} \pm 0.45$ & $13.01^{\mathrm{a}} \pm 0.24^{* *}$ & $12.15^{\mathrm{e}} \pm 0.09$ \\
D & Diclofenac Sodium plus Vitamin $\mathrm{B}_{12}$ before meal & $12.05^{\mathrm{e}} \pm 0.13$ & $11.5^{\mathrm{f}} \pm 0.15$ & $10.72^{\mathrm{g}} \pm 0.09$ \\
E & Diclofenac Sodium plus Vitamin $\mathrm{B}_{12}$ after meal & $12.44^{\mathrm{d}} \pm 0.37$ & $12.09^{\mathrm{e}} \pm 0.29$ & $13.04^{\mathrm{a}} \pm 0.19^{* *}$ \\
\hline
\end{tabular}

The values given above represent the mean \pm standard deviation (SD) of 9 mice $(n=9)$

$* *=$ Significant at $\mathrm{p}<0.01 \quad *=$ Significant at $\mathrm{p}<0.05$

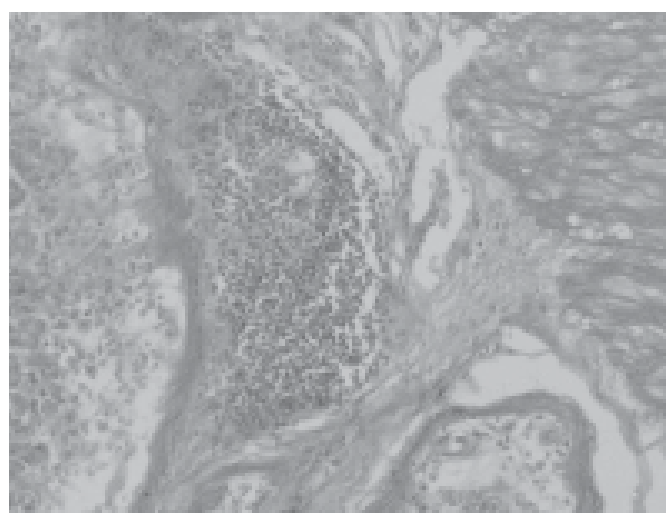

Figure-1: Histopathological section of stomach showing infiltration of mononuclear cell between the gastric mucosal layers ( $\mathrm{H} \& \mathrm{E}$ x100)

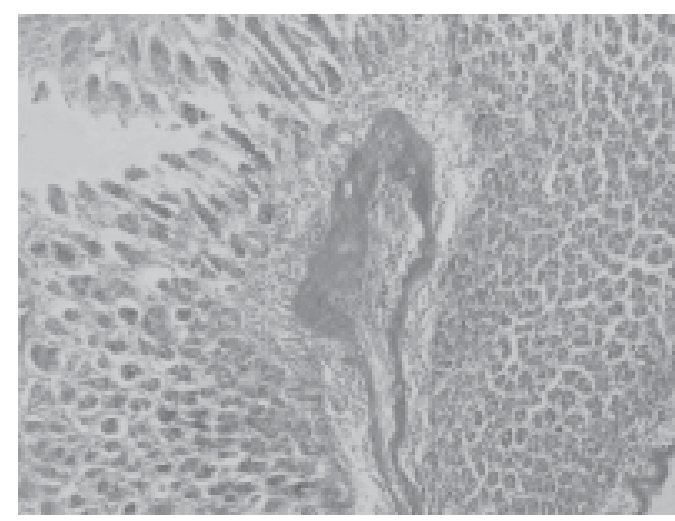

Figure 2: Histopathological section of stomach showing infiltration of mononuclear cell with ulcerative congestion between the gastric mucosal layers (H\&E x100) 
Gastric Mucosa and Liver with Diclofenac Sodium

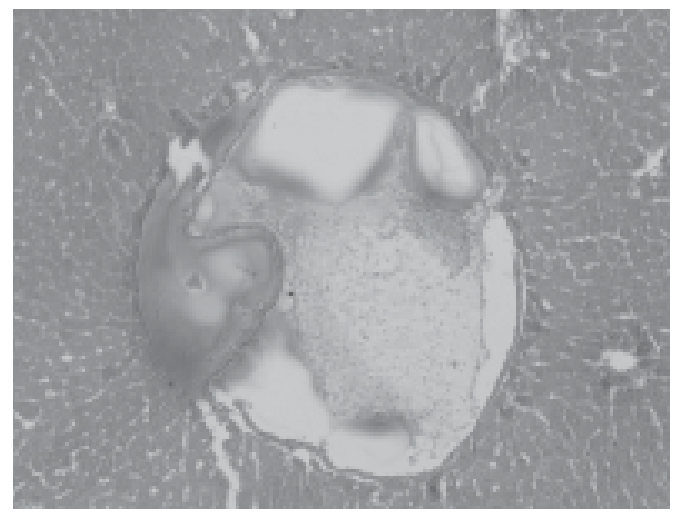

Figure 3: Histopathological Section of Liver Showing fatty changes characterized by minute vaculation (H\&E x100)

\section{Discussion}

In the present study, some hematological parameters such as TEC and $\mathrm{Hb}$ and pathological changes were studied in animals administered with diclofenac sodium. The increased total erythrocyte count and total hemoglobin content (gm/dl) among the animals treated by diclofenac sodium and vitamin $\mathrm{B}_{12}$ in full stomach might be due to liver invigorating effect of Vitamin $B_{12}$ and failure of the drugs to cause harm to gastric mucosa when it is taken with feed compared to empty stomach. Such findings were agreed by Dilov $^{8}$ who reported that cyanocobalamin containing biofer showed a better anti-anemic effect in anemic albino rats. This result indicates that vitamin $\mathrm{B}_{12}$ has no positive effect unless if administered in full stomach. This might be due to the food folic acid unavailability to DNA synthesis in the process of erythropoiesis. Here vitamin $B_{12}$ is assumed to activate folic acid in this process ${ }^{10}$.

On the other hand the decreased values of total erythrocyte count and total hemoglobin content (gm/dl) in the animals treated by Diclofenac sodium in empty stomach might be an effect of maturation failure of red blood cells due to faulty absorption of Vitamin $\mathrm{B}_{12}$. which might be linked to oral administration of diclofenac sodium on fasting condition. Similar findings were also reported by Richard ${ }^{6}$, Ramesh ${ }^{7}$, Sharma ${ }^{9}$ and Bhaumik $^{9}$.
Article

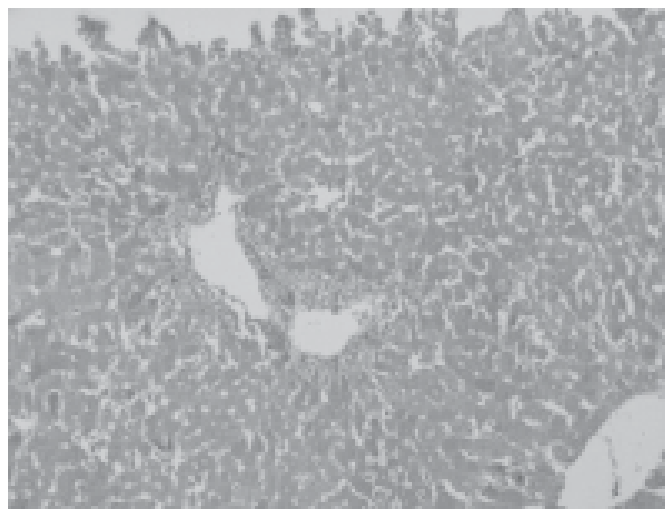

Figure 4: Histopathological section ofliver showing infiltration of mononuclear cell with ulcerative congestion around the central vein (H\&E x100)

Gross pathological changes in liver and stomach might be the consequence of administration of diclofenac sodium in empty stomach. No such changes were observed in control group. The centrilobular necrosis with congestion in liver observed in this present study may be due to hypoxic condition resulting from fall of systemic blood pressure by recurrent hemorrhage from gastric mucosa in empty stomached animal treated with diclofenac sodium or diclofenac sodium plus Vitamin $B_{12}$. Lipotrophic factors such as choline and are necessary for removal of fat from liver as well as for the formation of phospholipids. Phospholipids are essential for the transport of fat. This food factors absorption was less due to ulceration of stomach leads to the rapid accumulation of fat in liver. There was also infiltration of mononuclear cells between the gastric mucosal layer in empty stomached animal treated with diclofenac sodium or diclofenac sodium plus Vitamin $B_{12}$. No such histopathological changes were observed in control group and in the animals treated with diclofenac sodium or diclofenac sodium plus Vitamin $B_{12}$ in full stomach. In the present study, it has been observed that the oral administration of this drug significantly decreased the total erythrocyte Count and hemoglobin content in animals in empty stomach which was treated with only diclofenac sodium and also in empty stomach animal which was treated with diclofenac sodium 


\section{Article}

plus vitamin $\mathrm{B}_{12}$. In empty stomach animal, congested liver and hemorrhage with ulcer in stomach was found. No such lesion was observed in control group. Central vein congestion, sinusoidal congestion, infiltration of mononuclear cells around central vein, slightly swollen hepatocytes and fatty changes characterized by minute vaculation found in liver in empty stomached animal treated with only diclofenac sodium and also in empty stomached animal which was treated with diclofenac sodium plus vitamin $\mathrm{B}_{12}$. There was also infiltration of mononuclear cells between the gastric mucosal layer in empty stomach animal treated with only diclofenac sodium and also in empty stomach animal which was treated with diclofenac sodium plus vitamin $B_{12}$.

\section{Conclusion}

From the above findings we may conclude that intake of diclofenac sodium along with or without vitamin $\mathrm{B}_{12}$ on fasting condition may produce harmful effect on liver and stomach of an animal and the harmful effect of diclofenac sodium on erythropoiesis may be counteracted by concomitant intake of vitamin $B_{12}$.

\section{Author affiliations}

1. Md. Nazmul Hoque, DVM; MS student, Department of Physiology, Bangladesh Agricultural University, Mymensingh-2202

2. *Md. Kamrul Islam, Associate Professor, Department of Physiology, Bangladesh Agricultural University, Mymensingh-2202 E mail: K_islam88@yahoo.com.

3. Md. Monirul Islam, DVM; MS student, Department of Physiology, BAU, Mymensingh-2202

4. Md. Mustafizur Rahman Chowdhury, DVM; MS student, Department of Physiology, BAU, Mymensingh-2202

5. Md.Mizanur Rahman, Associate Professor, Department of Surgery and Obstetrics, BAU, Mymensingh-2202

* For correspondence
Gastric Mucosa and Liver with Diclofenac Sodium

\section{References:}

1. Hochbereg MC. NSAIDs: mechanisms and pathways of action. Hos. Pract. 1989;15: 185-198.

2. Scholer DW, Boettcher I, Schweizer A. Pharmacology of diclofenac sodium. Am. J. Med. 1986; 80(4B): 34-38.

3. Gutting BW, Updyke LW, Amacher DE. Diclofenac activates $\mathrm{T}$ cells in the direct popliteal lymph node assay and selectively induces IgG(1) and IgE against co-injected TNP-OVA. Toxicol. Lett. 2002; 131(3):167-180.

4. Jonnes RD, Baynes RE, Nimitz CT. Nonsteroidal anti-inflammatory drug toxicosis in dogs and cats: 240 cases. J. Am. Vet. Med. Assoc. 1992; 201: 475477.

5. McDonald P, Edwards RA, Greenhalgh JF. Minerals in animal nutrition. $4^{\text {th }}$ edn. English language Book Society; 1987. pp. 106-108.

6. Richard Adams H.Veterinary pharmacology and therapeutics. $7^{\text {th }}$ edn. 1995.pp: 534-538.

7. Ramesh N, Jayakumar K, Narayana K, Vijayasarathi Sk. Evaluation of diclofenac sodium for organ toxicity. Ind. J. Toxicol. 2001; 8(2):127-132.

8. Dilov P, Antonov S, Boiadzhieva A, Iotov M. Pharmacological and clinico-pharmacological studies of a combination preparation for calves having antianemia and general tonic action. Ve.t Med. Nauki. 1983;20(5-6): 87-98.

9. Sharma MC, Dixit SK, Lal SB, Baig J, Anup B, Bhaumik A. Effect of a herbal preparation in experimentally induced hepatopathy in goats. Ind. J. Anim. Sci. 1993; 63(6): 606-610.

10. Guyton AC, Hall WD. Text Book of Medical Physiology. New Delhi: Elseveir ;2006.pp: 426427. 